\title{
La expresión caballeresca en las fiestas reales barrocas españolas"
}

\author{
Jordi BERMEJO GREGORIO \\ Universitat de Barcelona \\ j.bermejo.gregorio@gmail.com
}

\section{RESUMEN}

En las fiestas poético-musicales del siglo XVII, una característica fundamental fue la representación de las autoridades mediante figuras relacionadas con la fantasía y el no realismo propios del mundo épico y caballeresco. Esta expresión caballeresca fue evolucionando y desarrollándose a partir de los torneos y mascaradas del siglo XVI para llegar a su estado más alto y avanzado con las fiestas reales barrocas. Esta determinada expresión provino de las tradiciones caballerescas extranjeras o relacionadas con ellas - como el ciclo de Amadís-, ya que la tradición épico-medieval propiamente hispana no tenía el distanciamiento de la realidad necesario para ser el lenguaje de auto-expresión de la dramaturgia poéticomusical.

Palabras clave: Teatro palaciego, espectáculo barroco, materia caballeresca, épica medieval.

\begin{abstract}
A basic characteristic in the poetic-musical plays of the seventeenth century was the authorities' representation through an extraordinary and unreal world, representative of the epic and chivalric world. This singular expression was developed from the tournaments and masquerades of the sixteenth century to become an important part of the palace theater. This characteristic aesthetic had its origins in the foreign chivalric traditions, such as the Amadis cycle, since the Hispanic medieval tradition had no remoteness from reality, which is necessary to be the language of self-expression that need the poetic-musical drama.
\end{abstract}

Keywords: Palace Theater, baroque spectacle, chivalric theme, medieval epic.

Sumario: 1. Las fiestas reales barrocas, 2. Ciclo carolingio o francés, 3. Ciclo bretón o anglosajón, 4. El ciclo de los Amadises o libros de caballería hispana.

* Este trabajo se inscribe dentro de los proyectos del Grupo de Investigación Consolidado «Aula Música Poética» (2009 SGR 941), financiado por la Generalitat de Catalunya. 


\section{Las fiestas reales barrocas}

En el transcurso de la evolución de los espectáculos cortesanos surgió la necesidad de encontrar otras formas de expresión mucho más elevadas y distinguidas acordes a la creciente oficialización y el pragmatismo político e ideológico de estos espectáculos-ceremonias. Torneos y justas dramatizadas, momos y mascaradas y églogas pastoriles y piscatorias fueron los primeros exponentes de la teatralización de los espectáculos y actos oficiales de las cortes entre la Baja Edad Media y el Renacimiento ${ }^{1}$. En el ámbito general y social de las fiestas cortesanas nació la fiesta real barroca, es decir, el espectáculo palaciego poético-musical ${ }^{2}$. Pero cuando se avanzó en la creación de fiestas reales organizadas exclusivamente por y para una autoridad distinguida, con la evolución y explosión de las artes plásticas, de la música y la intromisión de ambas cada vez más en el ámbito del teatro, cuando se singularizaron oficialmente los espectáculos $\operatorname{cortesanos}^{3}$, un pastor de una égloga -el espectáculo cortesano renacentista más refinado y culto hasta la fecha- ya no podía expresar y reflejar la figura al completo de un rey del siglo XVII. Era menester una expresión mucho más acorde con la condición superior del retratado. El elemento fantástico y no realista es, junto a la unión artística y la «ocasionalidad», una de las tres características principales del género de las fiestas reales barrocas españolas ${ }^{4}$.

Desde la primera etapa de la creación de la fiesta real barroca, en el género poético-musical en España - como en toda Europa-, siempre el tema sobre el cual versaba la trama y la materia que fabularía la fiesta fue lo fantástico y no realista. Y debía de ser así por la singularidad y naturaleza de los retratados. La intensificación de la compleja «ocasionalidad» $»^{5}$ y de la opulencia —efectuada mediante costosísi-

\footnotetext{
${ }^{1}$ T. Ferrer Valls (1991), p. 35.

${ }^{2}$ La fiesta cortesana pertenece a un estadio más genérico y superior, mientras que la fiesta real — por la naturaleza autorepresentativa y refleja del homenajeado que tiene- es una parte de esa realidad. La fiesta cortesana es el hiperónimo y la fiesta real, las mascaradas, los carros triunfales, mojigangas, arcos y construcciones efímeras, entre otros eventos y espectáculos, son los hipónimos.

${ }^{3}$ «La fiesta obtiene la consideración de un espectáculo cuya complejidad es superior a la del teatro, con el que guarda ciertas relaciones, de índole peculiar», F. López Estrada (1982), p. 292.

${ }^{4}$ En la tesis doctoral que estoy actualmente acabando - La dramaturgia poético-musical de Antonio de Zamora - , realizo una reteorización interdisciplinaria del género de las fiestas reales barrocas españolas agrupando todos los rasgos y observaciones de este tipo de espectáculos cortesanos en esas tres características.

5 Según Hans-Georg Gadamer, «ocasionalidad quiere decir que el significado de su contenido se determina desde la ocasión a la que se refiere, de manera que este significado contiene entonces más de lo que contendría si no hubiese tal ocasión», H-G. Gadamer (1977), p. 194.
} 
mos montajes que solamente podían permitirse la realeza y las principales casas nobles- propició que se buscara en divinidades y héroes legendarios la expresión de esos reyes, de esos príncipes, infantas o nobles de alta alcurnia ${ }^{6}$. Entonces fue cuando el elemento pastoril y bucólico se vio relegado a un secundario plano en esta expresión, únicamente de ambientación sensible y estética. Los mundos de la mitología grecolatina y de la épica de la caballería - sin contar con el alegorismo directo de algunas piezas - se convirtieron así en las expresiones pragmáticas adecuadas para el espectáculo de los reyes. Es el único modo en que los soberanos del barroco pueden ser expresados y reflejados como lo que se les consideraba: mediante la fábula, la fantasía, la magia, la espectacularidad, el asombro y la falta de realismo cotidiano propio de su condición. El distanciamiento de lo cotidiano y realista era fundamental, además, para que cupiera en el espectáculo tanto las significaciones oficiales — naturaleza panegírica de la monarquía - como las extraoficiales - críticas directas a personalidades de la corte, de una u otra ideología, que por el decoro no podían efectuarse literalmente ${ }^{7}$ -

Después del tema ambientado en el mundo mitológico clásico, la siguiente expresión de lo fantástico y no realista en las fiestas reales se centra en las leyendas y episodios de corte medieval, recogidas y agrupadas en la épica del género caballeresco $^{8}$. La evolución de esta materia en la cronología e historia de las fiestas reales es constante y paralela a la de la mitología, debido a que ambas son expresión y estética fantástica y no realista. Aunque no tan común como el tema mitológico, es también materia que cumple con igual función de autoexpresión, lirismo, distanciamiento de la realidad y también recreo elitista ${ }^{9}$. Este hecho no debe extrañar por las características de grandeza, aires legendarios y distinción humana muy por encima del común de los mortales, demostrados mediante la victoria ante seres irrea-

${ }^{6}$ «Para la que llega a ser la fiesta teatral de tipo cortesano, se tiene preferencia por la temática fantástica y no cotidiana - las fábulas mitológicas y las historias idealizadas del mundo pastoril, con varios niveles de personajes sobrehumanos y sobrenaturales-. Por supuesto, el gusto por los efectos escénicos especiales y por los magos, dragones, montañas mágicas, brujas, dioses y lo demás se podía costear solamente por la familia real o por las casas de la nobleza», L. Stein (2006), p. 100.

${ }^{7}$ Con estas palabras, pues, reafirmo que la visión que defiendo en cuanto a la concepción de las fiestas reales es tanto de alabanza y autoexpresión de reyes como crítica política, pues todas estas ideas y significaciones son elementos relativos a la «ocasionalidad», el elemento conceptual de la fiesta real, que está expresada mediante la fantasía y el no realismo, el elemento estético de la fiesta. Todos estos temas los desarrollo exhaustiva y profundamente en mi citada tesis doctoral.

${ }^{8}$ F. López Estrada (1982), pp. 294-295.

${ }^{9}$ «La pasión por las aventuras caballerescas de aquellos lectores pertenecientes sobre todo a la clase noble, propició la difusión de la costumbre de representar episodios de libros de caballerías en las fiestas reales», C. Demattè (2004b), p. 181. 
les de tremenda y terrorífica naturaleza pero verosímiles en la creencia caballeresca; ostentación espectacular caballeresca ${ }^{10}$. Precisamente sobre el escenario el espectador podía observar montajes que «resultaban relacionables con los libros de caballerías y con la de otras especies de ficción en que aparecen animales monstruosos, enanos, gigantes, etc. ${ }^{11}$. Aunque mortales, Tristán, Isolda, Orlando, Palmerín, Angélica, Medoro, Amadís de Gaula y otros personajes pertenecientes a la épica medieval y a la literatura caballeresca eran tipos que podían sin ningún problema representar y expresar el ideal y el comportamiento de seres eternos y poderosos sin perder el sentimentalismo que a sujetos de semejante perfil se les requiere. La imagen de estos héroes resultaba a la práctica la misma que dioses o semideos mitológicos. Aunque, eso sí, con diferencias notables en cuanto, por ejemplo, a la relativa proximidad temporal de las leyendas (que no en la finalidad estética, que es lo que aquí nos interesa). El halo etéreo y sobrehumano con que la tradición había pintado a los héroes épicos medievales los recordaba y los reconocía ${ }^{12}$ junto con el maravilloso imaginario y animalario propio de estas leyendas permitía que el rasgo fantástico, mágico y no realista efectuase esa función de expresividad excelsa de la persona homenajeada en la fiesta. Este rasgo de fantasía y maravilla posibilita la enorme espectacularidad escénica y dramática, siendo este un aspecto intrínseco del género de las fiestas reales. La ausencia de los caracteres mágicos y fabulosos es lo que diferencia las comedias caballerescas e inspiradas en el romancero u otras tradiciones medievales de las fiestas reales inspiradas y basadas en el género épicocaballeresco $^{13}$, aun habiendo sido estrenadas y creadas muchas comedias para palacio - como es el caso del teatro palaciego de tema histórico de Francisco Bances

${ }^{10}$ Esto se comprueba por el hecho de que, a la hora de hacer una adaptación del contenido de una novela caballeresca, «la práctica más difundida sea la selección de los episodios más espectaculares con dragones alados, sierpes bravas y castillos volantes», C. Demattè (2004b), p. 183.

${ }^{11}$ F. López Estrada (1982), p. 296.

12 «Los espectadores gozaban con estas demostraciones porque reconocían en ellos esta relación con la fábula imaginada que así se convertía en una realidad vivida en la tensión regocijada de la fiesta», F. López Estrada (1982), p. 297.

${ }^{13}$ Como datos clarividentes de esta diferenciación estética y expresiva, la investigadora italiana Fausta Antonucci analiza las comedias caballerescas de Lope de Vega El Marqués de Mantua (1596), Los palacios de Galiana (entre 1597 y 1602), La mocedad de Roldán (compuesta entre 1599 y 1603) y Las pobrezas de Reinaldos (probablemente de 1599) y concluye que «nunca, ni siquiera en las piezas cuya intriga podía dar pie a un desarrollo meramente fantástico, Lope se ajusta a un tratamiento de cuento de hadas, orientado exclusivamente a la diversión espectacular; y eso a pesar de lo novelesco de la materia tratada, de sus conexiones con una práctica escénica cortesana y de su ambientación fuera de la España contemporánea», F. Antonucci (2006), p. 75. 
Candamo $^{14}$ - Esta diferencia estética demuestra que no todo lo que se representa en palacio es fiesta real, género poético-musical.

Relativo a este punto, es importante constatar que la temática caballeresca en las fiestas reales a veces es tratada como una característica definitoria de un subgénero cuando, en realidad, atiende únicamente a una cuestión estética y de expresión, exactamente igual que ocurre con las fiestas reales de temática mitológica y aún más de tratamiento alegórico ${ }^{15}$. Es una variación estética, no conceptual del género de las fiestas reales, pues, al fin y al cabo, las materias mitológicas, épicocaballerescas y alegóricas tienen un mismo fin: la autorepresentación de la persona homenajeada. Alejandra Pachecho y Costa declara lo siguiente en relación a la fiesta real El jardín de Falerina (1648) de Calderón de la Barca:

Pese a que dentro de este subgénero abundan las comedias de tema mitológico, está claro que El Jardín de Falerina no puede calificarse como comedia mitológica: el único personaje sobrenatural es Falerina, hija de Merlín y el tratamiento de los personajes mortales con ella se aleja mucho de los esquemas de las comedias propiamente mitológicas de Calderón. ${ }^{16}$

Por supuesto, Falerina es el único personaje de naturaleza sobrenatural de la historia, responsable, pues, de toda la carga directa de magia en la trama. Pero este hecho no señala que Calderón trate de manera diferente lo que hace con los personajes mitológicos. Más bien al contrario: el hecho de que solamente aparezca Falerina como figura fantástica y mágica demuestra que, como los personajes mitológicos grecolatinos, Calderón y todos los dramaturgos que crearon piezas de estas materias seguían y respetaban - siempre con licencias derivadas de la «ocasionalidad»— las fuentes épicas y caballerescas con un elemento enorme de fantasía, imaginación y no realismo, igual que en el caso de las fuentes grecolatinas. Podrían añadirse atributos mágicos y fantásticos a personajes mortales como Rugero o Marsilio, acrecentando la espectacularidad y el asombro escénico, pero esto no variaría en absoluto la finalidad de la temática caballeresca en el género debido a lo fantás-

14 «Bances no escondía la función pedagógica que intentaba cumplir», C. Sanz Ayán (2006), p. 171. Así se puede comprobar incluso en fiestas reales de temática mitológica o caballeresca.

${ }^{15}$ La materia caballeresca en la que se basan algunas piezas palaciegas llevó a Ignacio Arellano a describir y analizar su estructura, concluyendo que la naturaleza épica y caballeresca de estas es eminentemente palaciega, no posible ni efectiva en el espacio del corral: «Con estructura de enredo, pero situadas en lugares y/o tiempos exóticos, en cortes italianas, Bohemia, Francia o Escocia, con personajes nobles y argumentos a menudo inspirados en refinados mundos literarios (novelescos, cortesanos)», I. Arellano (1995), p. 503.

${ }^{16}$ A. Pacheco y Costa (2003), p. 83. 
tico de sus orígenes. La razón principal de la utilización de la materia épica, pues, es el contenido del elemento fantástico, heroico y no realista de su misma naturaleza. Así pues, todo es cuestión de estética alejada y desplazada del realismo que expresa la naturaleza oficialmente excelsa y superior de las personas a las que se dedica la fiesta y por las que se ha creado el espectáculo; es una variación estética, no conceptual del género de las fiestas reales, pues, al fin y al cabo, las materias mitológicas, épico-caballerescas y alegóricas tienen un mismo fin.

No obstante, la materia caballeresca en las fiestas reales barrocas españolas es bastante más reducida y, en términos generales, se puede sintetizar en tres líneas de materia épica medieval europea. Como ocurre con la materia mitológica, la forma de tratamiento y de adaptación tiene una serie de posibilidades, que van desde una recreación bastante fidedigna de la fuente a una versión libre y alejada de la historia caballeresca ${ }^{17}$. Aunque hay más tradiciones medievales y caballerescas - como la germana o la nórdica-, encontramos, pues, el tema extraído del ciclo carolingio o francés, el tema propio del ciclo bretón o anglosajón y el ciclo de los Amadises o libros de caballería hispana por ser estas y no otras las que aparecen directa o indirectamente en las fiestas reales barrocas españolas.

\section{Ciclo carolingio o francés}

En la materia francesa medieval sobresalen los personajes relacionados con Carlomagno y su sobrino Roldán recogidos originariamente en La Chanson de Roland (siglo XI), aunque, como es sabido, las versiones que se utilizaron de base en la época y que más se aproximaban al perfil fantástico y caballeresco fueron las que recogieron los poemas épicos Orlando innamorato (1486) de Matteo Maria Boiardo (1441-1494) y, especialmente, Orlando furioso (1516) de Ludovico Ariosto (14741533). Como se deduce de ello, cualquier relato de estas obras puede ser - y fuemateria de ambientación argumental y estética épico-caballeresca para el género poético-musical, sobresaliendo en la fiesta española ${ }^{18}$-igual que ocurre con la materia mitológica clásica - los episodios de honda carga amorosa como son los episodios interconectados de Marfisa, Rugero, Falerina, Lisidante y Bradamante y el de Angélica y Medoro, historia que provoca los celos del héroe, Orlando ${ }^{19}$.

\footnotetext{
${ }^{17}$ Claudia Demattè advirtió cinco tipos de tratamiento de la materia caballeresca según las fuentes en el teatro del siglo XVII: I) obras con una estrecha relación con el hipotexto caballeresco; II) obras de ambientación caballeresca general y más libre; III) fabulación caballeresca parcial; IV) deformación original en parodia; y V) materia para otras piezas teatrales. C. Demattè (2004b), pp. 184-186.

${ }^{18}$ La difusión de la obra de Ariosto y su importante resonancia e influencia en la literatura española han sido tratadas por M. Chevalier (1966 y 1968) y J. J. Martín Romero (2004).

19 Aun no pudiendo considerar plenamente fiestas reales por varios motivos —entre los que se cuenta su naturaleza popular, no espectacular y, por lo tanto, no poético-musical- las piezas de Lope de Vega Los celos de Rodamonte (1588) y Belardo el furioso (1586-1595)
} 
Pedro Calderón de la Barca fue un gran exponente de las fiestas reales de temática caballeresca derivada del Orlando. Destacan, entre muchas otras, la zarzuela en dos jornadas El jardín de Falerina (1648), cuya música parcial se ha conservado con algunas variantes ${ }^{20}$, basada en los episodios del encuentro de Rugero con la bruja Falerina $^{21}$; y la última fiesta real del dramaturgo, Hado y divisa de Leonido y Marfisa (3, 4 y 5 de marzo de 1680, en las celebraciones de la boda de Carlos II con María Luisa de Orléans), que recrea la leyenda de los mellizos Leonido y Marfisa ${ }^{22}$. Estas dos no son los únicos exponentes del teatro caballeresco regio durante el reinado de Felipe IV $^{23}$.

son algunos de los primeros exponentes de calidad de la materia caballeresca ariostesca en el teatro hispánico. Algo semejante ocurre con las primeras representaciones en palacio de piezas de esta materia y estética caballeresca. La denominada comedia Rodamonte aragónes (representada en octubre de 1622 por la compañía de Alonso de Olmedo; N. D. Shergold y J. E. Varey (1982), p. 234, y Las pobrezas de Reinaldos (representada entre el 5 de octubre de 1622 y el 8 de febrero de 1623 por la compañía de Juan de Morales; N. D. Shergold y J. E. Varey (1982), p. 235, fueron representadas en el cuarto de la reina del Alcázar de Madrid, sin poder denominarse propiamente fiestas reales sino comedias palaciegas por la sencillez de su concepción, eminentemente teatral, no espectacular multiartística. Ambas no tienen una autoría concluyente y demostrable: para El Rodamonte aragonés La Barrera (1860), p. 589, y Subirats (1977), p. 470, lo relacionan con El valiente Lucidoro de Juan Bautista de Villegas; para Las pobrezas de Reinaldos ambos investigadores lo atribuyen a Lope de Vega.

${ }^{20}$ Biblioteca de Catalunya, Mus. MS 747/4. Cuatro tonadas de esta obra se encuentran en L. Stein (1993), pp. 436-439.

${ }^{21}$ No se debe confundir esta zarzuela de Calderón con una comedia homónima escrita conjuntamente con Francisco Rojas Zorrilla y Antonio Coello Ochoa de 1636 ni con un auto sacramental homónimo del mismo Calderón de 1675. Para un mayor conocimiento sobre la obra, su temática y la forma de dramatización del género caballeresco de Calderón, ver F. B. Pedraza Jiménez (2007) y L. Stein (2006), p. 101.

${ }^{22}$ Sobre la puesta en escena, el tema y el contexto histórico de Hado y divisa de Leónido y Marfisa, ver C. Sanz Ayán (2006), pp. 96-102.

${ }^{23}$ Calderón también creó Auristela y Lisidante, fiesta de 1660 dedicada a la infanta María Teresa de Austria, hija de Felipe IV, para la celebración de su boda con Luis XIV de Francia. La singularidad de esta pieza es que está inspirada en las aventuras de la novela bizantina Persiles y Segismunda (1617) de Cervantes, hecho este que hace que, aunque el tema sea próximo a la épica caballeresca y comparta el personaje de Lisidante con El jardín de Falerina, no se pueda englobar esta pieza dentro de la materia caballeresca francesa. Para un conocimiento mayor del argumento de esta fiesta y su comparación con Hado y divisa, ver D. Becker (2006), pp. 53-63. Entre muchas otras, debe tenerse en cuenta también la fiesta real El imperio de Alcina escrita por Juan Bautista Diamante y representada a fines de mayo de 1679 en el Coliseo del Buen Retiro — sin mucho éxito, sea dicho—. La fiesta está inspirada en el episodio de la joven Bradamante, su Amado Rugero y la hechicera Alcina. Para saber más sobre esta representación y su contexto histórico, ver C. Sanz Ayán (2006), pp. 86-87. 
Por otro lado, directamente del Orlando furioso de Ariosto tomaron dos dramaturgos del final del barroco la historia de amor de la princesa Angélica y del guerrero sarraceno Medoro, y del episodio de celos del héroe para el argumento y la temática de fiestas reales: Cómo se curan los celos y Orlando Furioso ${ }^{24}$, de Francisco Bances Candamo, estrenada el 22 de diciembre de 1692 en celebración del aniversario de la reina madre Mariana de Austria; y Angélica y Medoro ${ }^{25}$, de Antonio de Zamora, estrenada el 7 de abril de 1722 en celebración de las nupcias del príncipe heredero y futuro Luis I y la princesa Luisa Isabel de Orleans. Pero, como vamos diciendo, hay más muestras de la materia francesa en las fiesta reales barrocas españolas.

\section{Ciclo bretón o anglosajón}

La materia de Bretaña también suministra argumentos y temas al género poéticomusical por su alto grado de fantasía originaria. Sobresale, como es lógico, el ciclo artúrico sobre otras leyendas y relatos épicos ingleses. Las aventuras y fortunas de Arturo, Lancelot, Ginebra, Tristán e Isolda bien pueden nutrir, inspirar y ambientar una fiesta real, porque el requisito de fantasía y ruptura de la realidad se cumple extraordinariamente. Pero, como es de esperar, en la fiesta real española no se encuentra ninguna representación directa de esta materia épica anglosajona. Debe tenerse en cuenta en esta lista por incluir el Orlando furioso de Ariosto un gran número de relatos procedentes de este ciclo inglés - como por ejemplo Falerina, hija de Merlín, o el propio Orlando, que «no ha de ser ya un caballero del ciclo de Arturo, sino un paladín cristiano» ${ }^{26}$, tal y como Pedro Penzol define el tratamiento del caballero a manos de Boiardo- .

\section{El ciclo de los Amadises o libros de caballería hispana}

\footnotetext{
${ }^{24}$ Para profundizar en esta zarzuela de Bances Candamo, consúltese Pedro Penzol (1956a y 1956b) y Alice M. Pollin (1989).

${ }^{25}$ La autoría de esta zarzuela, considerada durante mucho tiempo por la crítica como de José de Cañizares, es muy probablemente de Antonio de Zamora. El primer documento que demuestra que no es de Cañizares es la crítica titulada Responde a d. Panuncio d. Armengol su dictamen satisfaciendo las objeciones hechas sobre la melodrama de Angélica y Medoro (BNE: VC/293/26), donde la crítica clasicista arremete en especial contra el responsable de los sainetes, José de Cañizares. La posición de Zamora como dramaturgo conocido en la corte y experimentado en actos oficiales de tal índole, gentilhombre de Felipe V, el estilo y la gran amistad con Cañizares son puntos que deben tenerse muy en cuenta para pensar que este melodramma salió de la pluma de Zamora. Véase también la documentación sobre la fiesta en I. López Alemany y J. Varey, El teatro palaciego en Madrid: 1707-1724: estudio y documentos, Woodbridge, Tamesis, 2006, pp. 22-24.
}

${ }^{26}$ P. Penzol (1956a), p. 322. 
Mientras que en el resto de Europa durante absolutamente toda la Edad Media existió una épica medieval con grandes rasgos fantásticos e irreales, en la península Ibérica esto es distinto. El alto nivel de realismo de la épica peninsular en comparación con la europea hizo que, con la llegada de la imprenta y la divulgación de obras de otros países en el inicio del renacimiento, se creara una literatura épica hispana más fantasiosa que sorprendiera al entretenimiento de los lectores. Así pues, esta literatura caballeresca del siglo XVI puede sintetizarse con el extraordinario Amadís de Gaula (publicada en 1508), supuestamente de Garci Rodríguez de Montalvo, el primer libro de caballerías español. En este libro se fundamentarían gran parte de los posteriores ejemplares del género. El mundo y la propia jerarquía cósmica basada en los ideales y actitudes del buen caballero incorporó el elemento fabuloso para la literatura peninsular. Los trece libros de la saga de Amadís dan fe de lo referencial que fue esta obra para el mundo caballeresco con el que a Alonso Quijano «se le secó el cerebro, de manera que vino a perder el juicio» ${ }^{27}$. Así que, muy claramente, la materia de los Amadises, Palmerines y la caballería propiamente hispana podía ser el motivo fantástico y falto en realismo (que no por ello en verosimilitud) que la expresión de la fiesta real barroca necesitaba.

Así fue: el ejemplo más notorio y categórico es La Gloria de Niquea, del conde de Villamediana. Estrenada el 8 de abril de 1622 en Aranjuez en celebración del aniversario de Felipe IV, la fiesta está inspirada en el episodio del Amadís de Grecia y la princesa Niquea, incluida en el Amadís de Grecia (1530), de Feliciano de Silva ( $\uparrow 1554)$, el sexto libro de la saga amadisiana. Es sintomático y muy clarividente que La Gloria de Niquea sea el primer espectáculo considerado poéticomusical ${ }^{28}$ de la corte española, sin discernir la materia de la que está inspirada. El hecho de que la estética escogida por el conde de Villamediana y otros ${ }^{29}$ sea la épica y caballeresca con altos elementos fantásticos y no realistas demuestra otra vez que la preferencia de la mitología clásica para las fiestas reales no es un rasgo indispensable de la concepción del mismo género, sino un asunto puramente de la expresión estética, de la expresión de la naturaleza elitista y regia del espectáculo y

\footnotetext{
${ }^{27}$ M. Cervantes (2004), p. 42

${ }^{28}$ E. Cotarelo y Mori (2000), p. 51, considera que Calderón crea el género poético-musical dividido en dos actos con El jardín de Falerina, aunque no advierte de la existencia y la capital importancia de La gloria de Niquea para la evolución del género poético-musical.

${ }^{29}$ Enmarcado en las celebraciones de los aniversarios de los jóvenes Felipe IV e Isabel de Borbón de 1622 se inscribe otro espectáculo regio de estética caballeresca. Querer por sólo querer, de Antonio Hurtado de Mendoza, fue estrenada en el Salón Grande del Real Alcázar de Madrid, el 1 de enero de 1623. Si bien es una creación menos espectacular que la de Villamediana y la materia caballeresca de la que se nutre no es ciertamente definida, también la estética y la temática caballeresca «en la línea de La gloria de Niquea permitía la fantasía y el despliegue de las invenciones y tramoyas, y a la vez respondía a los ideales, gustos y estilo propios del público cortesano», E. Borrego (2004), p. 352.
} 
la naturaleza de los destinatarios y retratados en él, relegando así su importancia a un relativo segundo plano. Lo importante era que posibilitase la espectacularidad en todos los sentidos, y esto lo permitía el elemento fantástico y no realista.

Como ocurre con la materia francesa, La gloria de Niquea no es la única muestra de la utilización del imaginario y estética caballeresca, en este caso, española. Otras fiestas reales de temática caballeresca hispánica son Palmerín de Oliva o la encantadora Lucelinda de Juan Pérez de Montalbán ${ }^{30}$, basada en El libro del famoso y muy esforzado caballero Palmerín de Oliva (1511) ${ }^{31}$; la zarzuela Las proezas de Esplandián y el valor deshace entuertos (1729), atribuida a Manuel de Armesto Quiroga e inspirada en el héroe de Las sergas de Espladián, de Garcí Rodríguez de Montalvo, «en la que se cuentan las hazañas del hijo del ilustre caballero de Gaula ${ }^{32}$; y la zarzuela Amor, ventura y valor y el invencible Amadís (1739), basada en la primera saga caballeresca del héroe de Gaula.

Igual que ocurrió con las fiestas de Bances Candamo y Zamora, la estética y la materia caballeresca en el género poético-musical español tuvo su época álgida aunque con un acento bastante homogéneo durante todo el periodo-, en las postrimerías del barroco, durante la primera mitad del siglo XVIII. De este modo se prueba que la idea de que el tema caballeresco en las fiestas reales era propio del final del siglo XVI y de primeras décadas del XVII es completamente errónea ${ }^{33}$.

${ }^{30}$ Tenemos noticia de que en el 23 de abril de 1686 y en días sucesivos la compañía de Manuel de Mosquera representó en el Coliseo del Buen Retiro al público una serie de piezas, entre las que una se denomina «la comedia de Palmerín, alumbrado el teatro y con sus tramoyas y ha habido mucha entrada»; N. D. Shergold y J. E. Varey (1982), p. 171, doc. 89. La descripción de los recursos técnicos del legajo insinúa que muy posiblemente se trate de una fiesta real comentada de Juan Pérez de Montalbán (1602-1638).

${ }^{31}$ El fuerte aprecio de Juan Pérez de Montalbán por el tema caballeresco se ratifica con otras piezas teatrales del mismo estilo - que no obligatoriamente pertenecientes al género de las fiestas reales-: la comedia El Florisel de Niquea - que dramatiza la aventuras del hijo de Amadís de Grecia y Niquea - y el auto El caballero del Febo - inspirado el libro de caballerías español El caballero del Febo el troyano (1576), obra de Esteban Corbera-.

${ }^{32}$ C. Demattè (2004a), p. 614. «En efecto, como veremos, Las proezas puede considerarse una zarzuela por la importante presencia de apuntes en música. Este elemento nos lleva a pensar que posiblemente fue compuesta a finales del siglo XVII o bien en las dos primeras décadas del s. XVIII [...]. El autor (¿Cuadra?, ¿[Manuel Francisco] Armesto y Quiroga?) debió de aprovechar el éxito aurisecular del teatro caballeresco para proponer a su público la re-escritura de Las sergas de Espaldián, en la que podían combinarse elementos de la comedia barroca — espectacularidad, honor y amor - con otros más bien característicos del s. XVIII — música instrumental, canto, aparatos escénicos—», C. Demmattè (2004a), p. 615616.

${ }^{33}$ De esta manera, se corrige esta idea de la mayoría de la crítica que, como Louise Stein, creía que «la cronología del teatro musical cortesano del reino de Felipe IV después de las fiestas de Aranjuez del 1622 [La gloria de Niquea], no presenta casi ninguna obra musical 
Asimismo, queda demostrado que los libros de caballería españoles del siglo XVI son una fuente igual de válida que la materia francesa o ariostesca para la expresión ostentosa y espectacular — en busca del asombro y la maravilla - de las fiestas reales.

En relación al tema de la materia caballeresca española, llama extraordinariamente la atención el hecho de que en la fiesta real barroca española se tuviera que recurrir a la épica medieval extranjera o inspirada en ella - como es el ciclo de los Amadises - teniendo España una tradición épica medieval tan rica como es la de los cantares de gesta y los romances castellanos. Ni el Cid Campeador, ni los siete Infantes de Lara, ni el Infante Arnaldos ni Fernán González aparecen nunca como base para el argumento y estética del género poético-musical. Y extraña más teniendo en cuenta que en estas leyendas el ideal de buen caballero, justo, fiel con el monarca, poderoso, pundonoroso y de cristianísimas creencias, valores y actitudes caracteriza a los protagonistas, cumpliendo gran parte de los atributos y del parecer ideológico que debían de tener los personajes principales reflejo de la monarquía y la alta nobleza- y que tan efectivo sería para la utilidad pragmática de la fiesta, no del teatro palaciego en general ${ }^{34}$.

Esta cuestión sobre la identidad castellana está concebida en torno a valores conceptuales y significativos. Aquí está el terrible error: no se debe mezclar el fondo con la superficie. Por supuesto que los ideales, valores e incluso la ideología mostrada en las fiestas reales del barroco puede ser - salvando la distancia histórica y social - análoga a la de la épica castellana tradicional. Pero lo que cuenta aquí es la expresión, la estética eminentemente caballeresca, el decoro fantástico, elegante y de tema que le permitiera ser ampuloso. En este aspecto sí que ha cambiado considerablemente en cuanto a la épica medieval castellana.

$\mathrm{Si}$ atendemos estéticamente a las tres principales materias caballerescas posibles para la ambientación de una fiesta real, veremos que, como con la mitología clásica, en esta está ausente el elemento realista y se potencia el fantástico y legendario, mientras que en la épica castellana se distingue de toda épica europea, precisamente, por ser la menos fantástica y atender a cuestiones puramente históricas desde una perspectiva —en comparación - extraordinariamente más realista y verosímil. Ramón Menéndez Pidal escribía sobre esta característica genuinamente castellana:

En medio de la relativa uniformidad del estilo en la canción narrativa de todos los países, los romances se distinguen por una extrema sencillez de recursos, que se manifiesta ora en la abstención y eliminación de elementos maravillosos o extraordinarios, ora en la parquedad ornamental, en la adjetivación reprimida, ora en la versificación asonantada monorrima; es la misma austeridad realista, la misma

basada en las historias de caballerías; se puede afirmar, más bien, que las obras del teatro musical cortesano miran hacia la mitología clásica en exclusiva», L. Stein (2006), p. 105.

${ }^{34}$ Ver la nota 12. 
simplicidad de forma que caracteriza nuestra literatura más representativa desde el primer monumento literario ${ }^{35}$.

En la épica castellana del Medievo no aparecían ni dragones, ni hipogrifos, ni brujas y magos, ni gigantes ni enanos, ni, lo más importante, los héroes de fuerte brazo que exterminaban centenares de enemigos con solo un espadazo ni mataban seres que, como ellos mismos, estaban muy por encima de la naturaleza liviana y mortal. La espectacularidad que permitía la épica castellana era demasiado llana y realista, es decir, demasiado poco novedosa y fascinante. La historia en el ciclo francés - a excepción del trasfondo verídico de Carlomagno y su sobrino-, en el ciclo artúrico y en los libros de caballerías hispánicos del XVI se arrincona hasta tal punto que llega a fabularse y a distanciarse de ella, cosa que no ocurre en Castilla ${ }^{36}$. La función informativa de los cantares de gesta y de los romances hace que la fabulación medieval y caballeresca no sea posible en los reinos hispánicos. La fantasía, pues, solamente pregonaba cada uno de los versos de Orlando, de Amadís y de tantas otras leyendas maravillosas e irreales, no las hazañas del Cid ni de Fernán González. Estas parten de una historia verídica que las otras leyendas medievales europeas o bien nunca han tenido o bien han perdido.

Para acabar de comprender exactamente esta idea de la necesidad del elemento fantástico caballeresco para la expresión de las fiestas reales, es harto ejemplar recordar las razones por las que Alonso Quijano se convirtió en don Quijote de la Mancha. Está en el perfil de los modelos que escoge y del mundo de héroes de la épica de que proviene la clave de la locura del hidalgo - a la vista de sus convecinos, claro está-. El escrutinio de la librería de don Quijote (I, VI) muestra perfectamente los cánones de héroes y de caballeros y la realidad que había configurado, lo que hizo que «le pareció convenible y necesario, así para el aumento de su honra como para el servicio de su república, hacerse caballero andante» ${ }^{37}$.

Ahora bien, Alonso Quijano quiere emular a los caballeros míticos de las leyendas carolingias, artúricas y amadisianas, no al Cid, ni a Bernardo el Carpio ni a Fernán González. Los dos tipos de caballeros y mundos mostraban los correctos y correspondientes valores necesarios para poder blandir una espada y capitanear los

\footnotetext{
${ }^{35}$ R. Menéndez Pidal (1991), p. 26.

${ }^{36}$ «Desde luego, la antigua epopeya española se distingue de las otras por tener un campo de inspiración más moderno que todas. Mientras la épica germánica relata asuntos de la edad de las invasiones, mientras la francesa deja de inspirarse en la historia con la época carolingia, hacia el siglo IX, en cambio, los temas conservados en la épica española van desde el siglo VIII, con el rey Rodrigo, hasta el XI, con el Cid, y aun hasta el XIII, con Alfonso VII y el rey Luis de Francia. Esto quiere decir que España se manifiesta más tenaz, más tradicionalista en mantener en actualidad un viejo género literario», R. Menéndez Pidal (1991), p. 10.

${ }^{37}$ M. Cervantes (2004), p. 43.
} 
versos del género épico. Pero estaba en la condición, actitud y naturaleza excelsa y casi sobrehumana, invencible ante inimaginables adversarios, lo que Alonso Quijano deseaba, lo que al hidalgo le atraía. Como él, los reyes querían y debían verse reflejados y expresados mediante esa «superlatividad» de gloria y poder en la que creían haberse engendrado, sintiéndose parte importante de la dimensión fabulosa y ultraterrenal que era la monarquía del siglo XVII ${ }^{38}$. Sería Alonso Quijano, un loco que, más allá del parecer, sabía quién era y quién podía ser o tendría la misma locura de los monarcas... Eso sí, a diferencia de los soberanos, don Quijote llegó a decir sinceramente en el lecho ya de muerte:

Dadme albricias, buenos señores, de que ya no soy don Quijote de la Mancha, sino Alonso Quijano, a quien mis costumbres me dieron renombre de Bueno. Ya soy enemigo de Amadís de Gaula y de toda la infinita caterva de su linaje; ya me son odiosas todas las historias profanas de la andante caballería; ya conozco mi necedad y el peligro en que me pusieron haberlas leído; ya, por misericordia de Dios, escarmentado en cabeza propia, las abomino ${ }^{39}$.

Cervantes tenía claras las posibilidades que la materia caballeresca, por ese distanciamiento fantástico, podía producir en el arte literario. Y, como se ha visto, la fabulación caballeresca - siempre que procedan de tradiciones de alto elemento fantástico y no realista - era un asunto perfectamente válido y fecundo para la expresión de unos espectáculos que estaban pensados por y para los reyes españoles.

\section{OBRAS CITADAS}

ANTONUCCI, Fausta: «La materia caballeresca en el primer Lope de Vega», en $L a$ comedia de caballerías: actas de las XXVIII Jornadas de Teatro Clásico de Almagro (Almagro, 12-14 de julio de 2005), Almagro, Universidad de CastillaLa Mancha, 2006, pp. 59-77.

ARELlano, Ignacio: Historia del teatro español del siglo XVII, Madrid, Cátedra, 1995.

BARRERA Y LEIRADO, Cayetano Alberto de la: Catálogo bibliográfico y biográfico del teatro antiguo español desde sus origenes hasta mediados del siglo XVIII, Madrid, M. Rivadeneyra, 1860.

${ }^{38}$ López Estrada, precisamente, defiende que Cervantes configuró el perfil de don Quijote (como figura risible-mascarada) en base a los torneos y justas medievalizantes (y para él ya arcaizantes) de las fiestas de que el escritor pudo ser espectador, tal y como lo señalan la multitud de relaciones que el estudioso encuentra en la obra de Cervantes; F. López Estrada (1982), pp. 307-327.

${ }^{39}$ M. Cervantes (2004), p. 1330-1331. 
BECKER, Danièle: «Hado y divisa de Leonido y de Marfisa. Adiós a las tablas palaciegas de Calderón», en Odette Gorsse y Frédéric Serralta (ed.), El Siglo de Oro en escena. Homenaje a Marc Vitse, Toulouse, PUM - Consejería de Educación de la Embajada de España en Francia, 2006, pp. 53-63.

BORREGO GUTIÉRREZ, Esther: «Poetas para la Corte: una fiesta teatral en el Sitio Real de Aranjuez (1622)», en Francisco Domínguez Matito y María Luisa Lobato (ed.), Memoria de la palabra, Madrid - Frankfurt am Main, Iberoamericana - Vervuert, 2004, pp. 337-352.

Cervantes, Miguel de: Don Quijote de la Mancha, Barcelona, Galaxia Gutenberg, 2004.

Chevalier, Maxime: L'Arioste en Espagne, Burdeos, Institut d'Études Ibériques et Ibéro-américaines de L'Université de Bordeaux, 1966.

: Los temas ariostescos en el romance y la poesía del siglo de oro, Madrid, Castalia, 1968.

COTARELO Y MORI, Emilio: Historia de la zarzuela, Madrid, ICCMU, 2000.

DEMATTÈ, Claudia: «Las proezas de Esplandián, comedia anónima del s. XVII, y su hipotexto caballeresco», en Memoria de la palabra: actas del VI Congreso de la Asociación Internacional Siglo de Oro (Burgos-La Rioja, del 15 al 19 de julio de 2002), Madrid - Frankfurt am Main, Iberoamericana - Vervuert, 2004a, pp. 613-628.

: «El teatro caballeresco del siglo XVII. Hacia una clasificación de las dinámicas transtextuales», en Actas del XIV Congreso de la Asociación Internacional de Hispanistas. Literatura Española: siglos XVI-XVII (New York, del 16 al 21 de julio de 2001), New York, Linguatext, 2004b, pp. 181-186.

FERRER VALLS, Teresa: La práctica escénica cortesana: de la época del emperador a la de Felipe III, London, Tamesis Book, 1991.

GADAMER, Hans-Georg: Verdad y Método I. Fundamentos de una hermenéutica filosófica, Salamanca, Sígueme, 1977.

LÓPEZ ESTRADA, Francisco: «Fiestas y literatura en los siglos de oro: la Edad Media como asunto "festivo" (El caso del "Quijote")», Bulletin Hispanique, 84 (1982), pp. 291-327.

MARTín ROMERO, y José Julio: «Nuevos datos sobre la influencia del Orlando furioso en España: Pedro de la Sierra frente a Ariosto», Revista de Literatura Medieval, 16.1 (2004), p. 95-119.

MENÉNDEZ PIDAL, Ramón: Flor nueva de romances viejos, Madrid, Espasa-Calpe, 1991.

PACHECo CostA, Alejandra: «Música, espacio escénico y estructura dramática en El Jardín de Falerina de Calderón de la Barca», Teatro: revista de estudios teatrales, 19 (2003), pp. 79-105.

PenZOL, Pedro: «Desde Ariosto hasta Bances Candamo», Archivum, VI (1956a), pp. 321-326. 
: «Angélica y Medoro en el Orlando furioso de Francisco Bances Candamo», Clavileño, VII, 39 (1956b), pp. 19-23.

PEDRAZA JiMÉNEZ, Felipe B.: «El jardín de Falerina y la recreación escénica de las caballerías», en Estudios sobre Rojas Zorrilla, Cuenca, Universidad de CastillaLa Mancha, 2007, pp. 219-234.

Pollin, Alice M.: «El Orlando furioso de Francisco Bances Candamo: importante interpretación dramático-musical del tema ariostesco», Cuadernos de Teatro Clásico, 3 (1989), pp. 95-106.

SANZ AYÁn, Carmen: Pedagogía de reyes: el teatro palaciego en el reinado de Carlos II, Madrid, Real Academia de Historia, 2006.

SHERGOLD, N. D., y VAREY, J. E.: Representaciones palaciegas: 1603-1699. Estudio y documentos, London, Tamesis Books, 1982.

StEIN, Louise K.: Songs of Mortals, Dialogues of the Gods, Oxford, Clarendon Press, 1993.

: «La música en la comedia cortesana caballeresca, y el poder del canto», en Felipe B. Pedraza Jiménez, Rafael González Cañal y Elena Marcello (ed.), La comedia de caballerías: actas de las XXVIII Jornadas de Teatro Clásico de Almagro (Almagro, 12-14 de julio de 2005), Almagro, Universidad de CastillaLa Mancha, 2006, pp. 99-120.

SUBIRATS, Rosita: «Contribution à l'établissement du repertoire théâtral à la cour de Philippe IV et de Charles II», Bulletin Hispanique, 79 (1977), pp. 401-479. 